\title{
Southern Ocean warming and increased ice shelf basal melting in the 21 st and 22 nd centuries based on coupled ice-ocean finite-element modelling
}

\author{
R. Timmermann • H.H. Hellmer
}

This is the authors' final version of a paper accepted by Ocean Dynamics, submitted on 26. June 2013.

The published paper is available from SpringerLink with DOI: 10.1007/s10236-013-0642-0

\begin{abstract}
We utilize a global finite element sea ice - ice shelf - ocean model (FESOM), focused on the Antarctic marginal seas, to analyse projections of ice shelf basal melting in a warmer climate. Ice shelf - ocean interaction is described using a three-equation system with a diagnostic computation of temperature and salinity at the ice-ocean interface. A tetrahedral mesh with a minimum horizontal resolution of $4 \mathrm{~km}$ and hybrid vertical coordinates is used. Ice shelf draft, cavity geometry, and global ocean bathymetry have been derived from the RTopo- 1 data set. The model is forced with the atmospheric output from two climate models: (1) the Hadley Centre Climate Model (HadCM3) and (2) Max Planck Institute's ECHAM5/MPI-OM coupled climate model. Results from experiments forced with their 20th-century output are used to evaluate the modeled present-day ocean state. Sea-ice coverage is largely realistic in both simulations; modeled ice shelf basal melt rates compare well with observations in both cases, but are consistently smaller for ECHAM5/MPI-OM. Projections for future ice shelf basal melting are computed using atmospheric output for the IPCC scenarios E1 and A1B. In simulations forced with ECHAM5 data, trends in ice shelf basal melting are small. In contrast, decreasing convection along the Antarctic coast in HadCM3 scenarios leads to a decreasing salinity on the continental shelf and to intrusions of warm deep water of open ocean origin. In case of Filchner-Ronne Ice Shelf (FRIS), this water reaches deep into the cavity, so that basal melting increases by a factor of four to six compared to the present value of about $90 \mathrm{Gt} / \mathrm{yr}$.
\end{abstract}

Alfred Wegener Institute, Helmholtz Centre for Polar and Marine Research, Bremerhaven, Germany

E-mail: Ralph.Timmermann@awi.de
By the middle of the 22nd century, FRIS becomes the dominant contributor to total ice shelf basal mass loss in these simulations. Our results indicate that the surface freshwater fluxes on the continental shelves may be crucial for the future of especially the large cold water ice shelves in the Southern Ocean.

Keywords Southern Ocean · ice shelves · climate prediction

\section{Introduction}

Melting of glaciers, ice caps, and ice sheets contributes to changes in global sea level. Given that most of the Antarctic Ice Sheet drains into floating glaciers or ice shelves, which serve as buttresses to the ice flow (e.g. Dupont and Alley, 2005), variations of ice shelf basal melting are an important component in the southern hemisphere's future ice mass budget.

In order to obtain an estimate of ice shelf basal melt rates in a warmer climate, we use a global sea ice-ice shelf-ocean model with high resolution in the Antarctic marginal seas that is forced with atmospheric output from global climate model projections. The climate models used in this framework are (1) the Hadley Centre Climate Model (HadCM3) and (2) the Max Planck Institute's ECHAM5/MPI-OM coupled climate model. Each of these models has been shown to score amongst the highest skills in an Antarctic evaluation of the IPCC's Fourth Assessment coupled model group (Connolley and Bracegirdle, 2007). We employ results for present-day climate (refered to as 20C experiments hereafter) and for the scenarios E1 and A1B suggested in the IPCC's Fourth Assessment Report (AR4). While $\mathrm{E} 1$ is a mitigation scenario in which emissions are sta- 
bilised by 2100 at $\approx 450$ ppmv $\mathrm{CO}_{2}, \mathrm{~A} 1 \mathrm{~B}$ is a more pessimistic (and as far as we know now: more realistic) scenario close to the centre of the range given by the Special Report on Emission Scenarios (SRES).

To obtain projections for ice shelf basal melting in these scenarios, we used the atmospheric output from the above-mentioned climate models to force the Finite Element Sea ice-Ocean Model (FESOM, Timmermann et al., 2009; Sidorenko et al., 2011) which has recently been augmented by an ice-shelf component (Timmermann et al. 2012, refered to as TWH12 hereafter). Ocean temperatures and ice shelf basal melt rates from these simulations have been applied as boundary conditions to an Antarctic ice sheet/shelf model (Payne et al., 2013).

Here, we present an analysis of the sea ice cover, oceanic heat and salt contents, and ice shelf basal melt rates from four FESOM simulations covering the two scenarios each with both forcing models. Present-day results are evaluated with reference to observations of ice extent and mean ocean temperature and salinity; ice shelf basal-melt rates are compared with independent estimates. Transition to a warmer climate is discussed with respect to the differences between scenarios and forcing models. Results are compared with the FESOM evaluation experiments with forcing from NCEP reanalysis data (TWH12), and with results from the Bremerhaven Regional Ice-Ocean Simulations (BRIOS) model (Timmermann et al. 2002a; Hellmer, 2004), which has been run with an identical suite of climate model outputs (Hellmer et al., 2012). The paper closes with a summary of the sensitivities and potential feedbacks relevant to ocean - ice shelf interaction in a warming climate.

\section{Model description}

FESOM is a hydrostatic, primitive-equation ocean model with an unstructured grid that consists of triangles at the surface and tetrahedra in the ocean interior. It has grown up from the Finite Element model of the North Atlantic (FENA) described by Danilov et al. $(2004,2005)$. It has been coupled to a dynamicthermodynamic sea ice model with a viscous-plastic rheology and evaluated in a global setup (Timmermann et al., 2009). An ice-shelf component with a threeequation system for the computation of temperature and salinity in the boundary layer between ice and ocean and the melt rate at the ice shelf base (Hellmer et al., 1998) has been implemented. Turbulent fluxes of heat and salt are computed with coefficients depending on the friction velocity following Jenkins (1991). The present setup uses a hybrid vertical coordinate and a global mesh with a horizontal resolution between 30 and $40 \mathrm{~km}$ in the offshore Southern Ocean, which is refined to $10 \mathrm{~km}$ along the Antarctic coast, $7 \mathrm{~km}$ under the larger ice shelves in the Ross and Weddell Seas, and to $4 \mathrm{~km}$ under the small ice shelves in the Amundsen and Bellingshausen Seas. Outside the Southern Ocean, resolution decreases to $50 \mathrm{~km}$ along the coasts and about 250-300 km in the vast basins of the Atlantic and Pacific Oceans. On the other hand, some of the narrow straits that are important to the global thermohaline circulation (e.g., Fram and Denmark Straits, and the region between Iceland and Scotland) are represented with high resolution (TWH12). Ice shelf draft, cavity geometry, and global ocean bathymetry have been derived from the RTopo-1 dataset (Timmermann et al., 2010) and thus consider data from many of the most recent surveys of the Antarctic continental shelf.

All FESOM simulations are initialized using temperature and salinity fields from NOAA's World Ocean Atlas 2001. Given that output variables differ between the two climate models, we use two slightly different forcing strategies for the simulations presented here: From HadCM3 output, we use 10-m wind velocity, air temperature and specific humidity at $1.5 \mathrm{~m}$ height, total precipitation, surface moisture flux (evaporation), downward long- and shortwave radiation, and surface pressure. The 20C data sets are applied for the period 1958-1999; E1 and A1B simulations extend from 2000 to 2199. From ECHAM5 output, we employ 10$\mathrm{m}$ wind velocity, 2-m air and dew point temperatures, incoming long- and shortwave radiation, precipitation and evaporation. Results from the 20C simulations are used for the period 1958-2000; E1 and A1B simulations extend from 2001 to 2099 (the latter being the end of the ECHAM5/MPI-OM model integration). Continental freshwater run-off is neglected in all cases; instead, the global mean surface salt flux in the open ocean is enforced to be zero as part of the forcing/coupling scheme.

\section{Results}

\subsection{Sea ice distribution}

Given that the sea ice cover in the Southern Ocean plays an essential role in shaping the water column density structure and modifying the momentum input at the ocean surface (see, e.g. Timmermann et al., 2002b or Hellmer et al. 2012), we evaluate sea ice extent in our simulations with respect to fields from passive microwave satellite data. For the $20 \mathrm{C}$ simulations in the present study (left column in Fig. 1), Southern Ocean ice extent compares well with observations (lower right panel in Fig. 1). Maximum sea ice extent is on the 

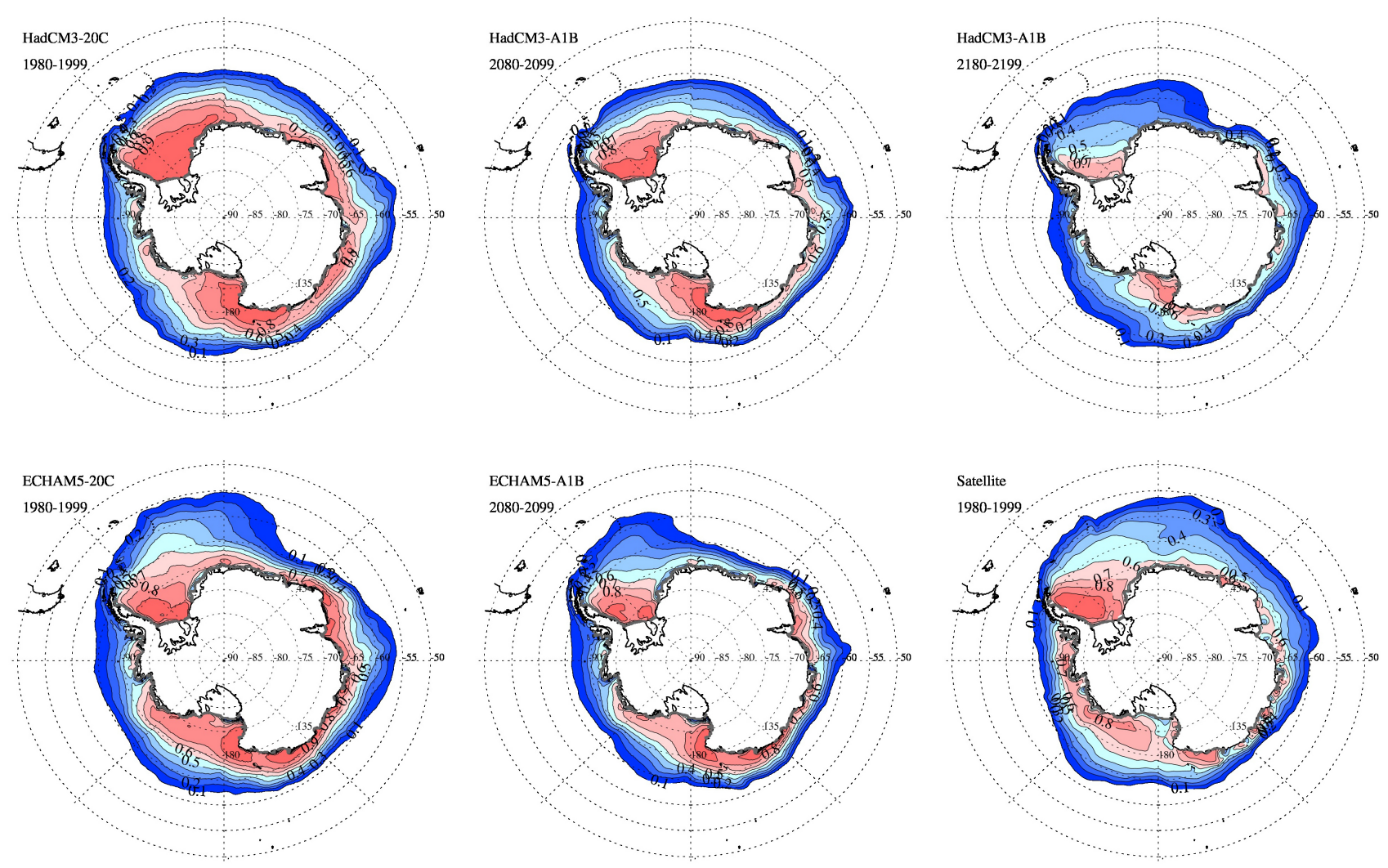

$\begin{array}{llllllllll}0.1 & 0.2 & 0.3 & 0.4 & 0.5 & 0.6 & 0.7 & 0.8 & 0.9 & 1.0\end{array}$

Fig. 1 Simulated and observed mean sea ice concentration. Top row: FESOM with HadCM3-20C forcing, averaged over 1980-1999 (left), A1B 2080-2099 (middle), and A1B 2180-2199 (right). Bottom row left: FESOM with ECHAM5-20C forcing, averaged over 1980-1999, middle: FESOM with ECHAM5-A1B forcing, averaged over 2080-2099. Lower right: Passive microwave satellite data (Cavalieri et al. 1996, Meier et al. 2006), averaged over 1980-1999.

low side for both HadCM3 and ECHAM5 forcing; the course of the ice edge is too zonal for HadCM3-20C, while in ECHAM5-20C only the ice extent in the Indian sector is distinctly too small.

Summer ice extent (defined as the area with an ice concentration of more than $15 \%$ ) closely resembles the $70 \%$ contour lines in the long-term mean concentration maps in Fig. 1. It is too large in HadCM3-20C simulations, implying that the seasonal cycle of sea ice growth and decay is underestimated. Mean summer ice extent in ECHAM5-20C is smaller and more realistic, especially in the Weddell Sea. The signature of the Ross polynya is too weak in both simulations, especially with HadCM3, indicating too weak offshore winds in the area.

For the period 2080-2099 in the A1B scenario (middle column in Fig. 1), mean sea ice coverage is reduced in both models, although preserving the characteristic patterns. In the HadCM3-A1B simulation, the ice edge has retreated in a rather uniform way and is again very zonal; for ECHAM5 forcing the Indian ocean stands out as the sector with the strongest decrease in ice extent. For the 2180-2199 average (top right panel in Fig. 1), only data from HadCM3 simulations are available; they indicate a further decline of Southern Ocean sea ice cover with the Weddell Sea now being mostly ice-free in summer.

Time series of annual mean ice extent (Fig. 2) show that the projections of future sea ice coverage in the Southern Ocean vary strongly between scenarios and only little between the two climate models used. In the simulations forced with HadCM3 data, sea ice cover starts to decrease already in the 1990s, reflecting the transient boundary conditions applied in the HadCM320C climate model run. Scenarios E1 and A1B substantially start to diverge from each other from 2050 onwards; a trend of $-2.3 \%$ per decade persists throughout the 21st and 22nd centuries only in HadCM3-A1B. For ECHAM5-A1B the trend is even larger $(-3.1 \%$ per decade) but the projection only extends until 2099. For E1, trends are consistently smaller $(-1.1 \%$ per decade 

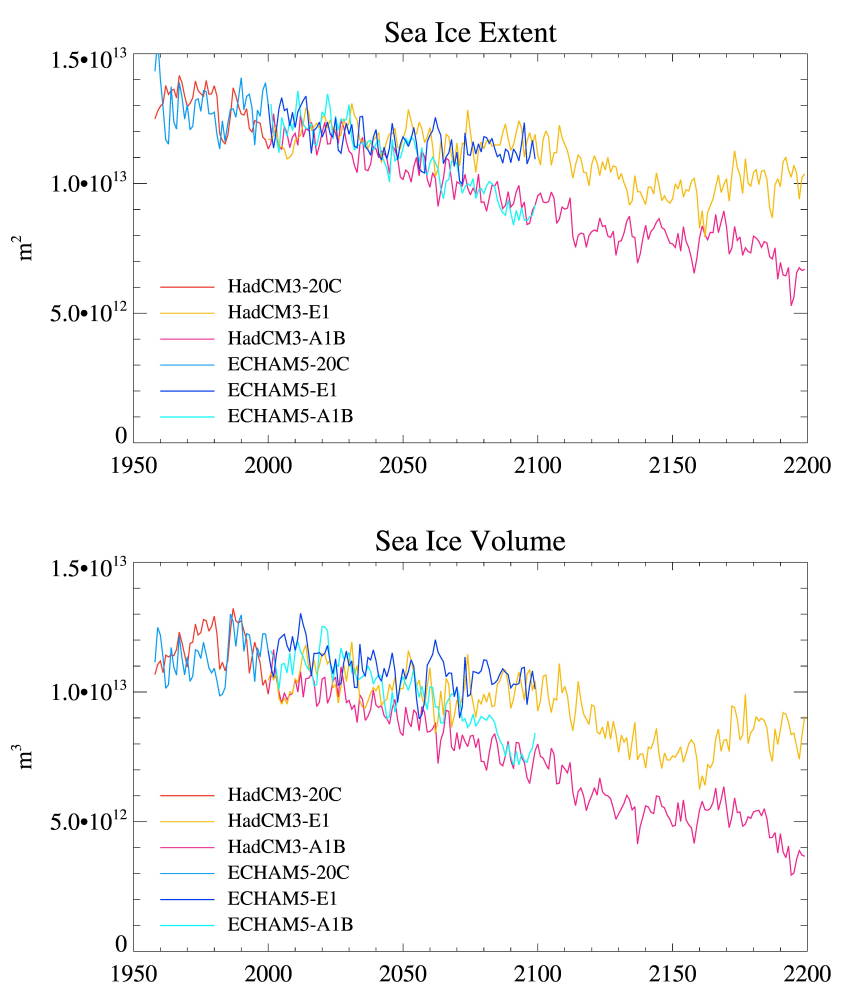

Fig. 2 Simulated annual mean Antarctic ice extent (top) and volume (bottom) in FESOM simulations forced with output for the 20th century and for scenarios E1 and A1B from the climate models HadCM3 and ECHAM5/MPI-OM.

for 2000-2199 in HadCM3-E1, -1.2 \% per decade for 2000-2099 in ECHAM5-E1).

Trends in sea ice volume are generally stronger than trends in sea ice extent: Sea ice volume in HadCM3A1B (ECHAM5-A1B) decreases by $3.2 \%$ (3.4\%) per decade.

For Arctic sea ice in our simulations (not shown) we find a very similar consistency between different models under the same scenario, and also a strong divergence beween the scenarios from 2050 onwards. Compared to present-day values, Arctic sea ice extent in the $21 \mathrm{st} / 22 \mathrm{nd}$ centuries is reduced by $10 \%$ (40\%) in the E1 (A1B) scenario. Arctic ice volume in the E1 (A1B) scenario is reduced by $20 \%$ (80\%) of its presentday value by 2100 , indicating again that ice thickness shrinks faster than ice concentration.

\subsection{Ocean heat content}

To analyze the ocean heat content in regions that are expected to influence ice shelf basal melting, we divide the Southern Ocean into sectors refered to as "Weddell Sea" (W), "Bellingshausen Sea" (B), "Amundsen Sea" (A), "Eastern Ross Sea" (ER), and "Western Ross Sea"

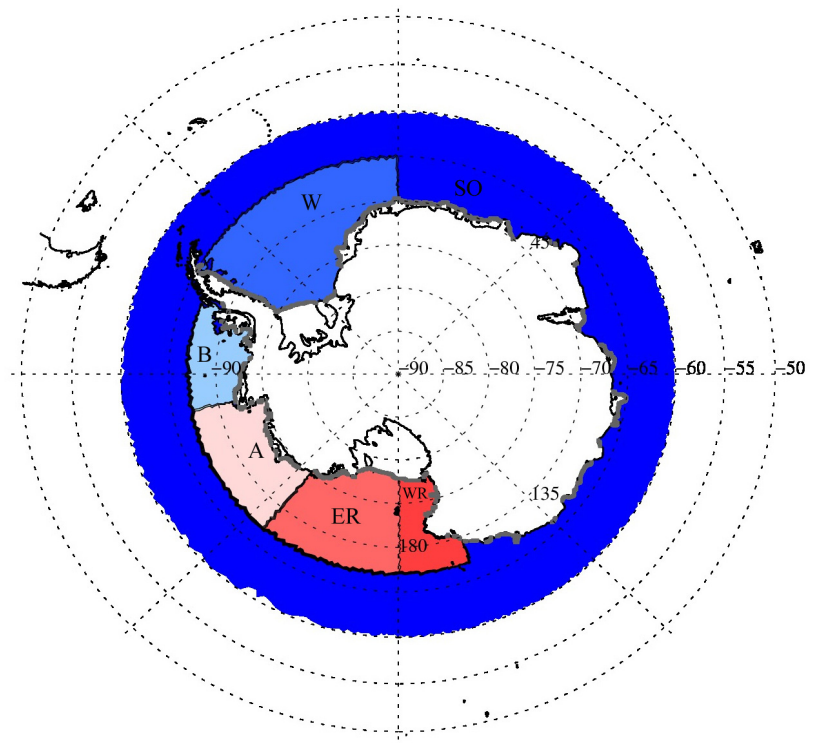

Fig. 3 Sectors used for the computation of mean temperatures (Fig.4). Each of the sectors is subdivided between the continental shelf and the deep ocean. $\mathrm{SO}=$ Southern Ocean, $\mathrm{W}=$ Weddell Sea, $\mathrm{B}=$ Bellingshausen Sea, $\mathrm{A}=$ Amundsen Sea, $\mathrm{ER}=$ Eastern Ross Sea, WR $=$ Western Ross Sea.

(WR; Fig. 3). Each of the sectors is subdivided into a "shelf" and a "deep" sector, with the boundary along the $800-\mathrm{m}$ isobath in the Weddell and Amundsen Seas and along the 700-m isobath in the other sectors. Mean temperatures are computed between $200 \mathrm{~m}$ depth and the bottom on the continental shelf, and between $400 \mathrm{~m}$ and $1000 \mathrm{~m}$ for the deep subsectors. The rationale behind this choice is (1) to exclude short-term variations that are most pronounced in surface waters, and (2) to mainly consider water that has the potential to enter the shelf from the deep sectors, and the sub-ice shelf cavities from the shelf subsectors. Additionally, a circumpolar "Southern Ocean" covering the whole water body south of $60^{\circ} \mathrm{S}$ is defined. Water in the sub-ice shelf cavities is excluded in all cases.

In contrast to the time series of sea ice extent, the evolution of ocean heat content (Fig. 4) differs more strongly between forcing models than between scenarios. Simulations forced with ECHAM5 output are generally cooler than those forced with HadCM3 data; the difference evolves during the first decades of the simulations (within the 20C time frame) and is consistent over all sectors and also for the Southern Ocean and global means. Compared with NOAA's World Ocean Atlas 2001, which is used as the initial state for all FESOM experiments, a cold bias in the simulations forced with ECHAM5 is evident for all sectors and also for the circumpolar Southern Ocean. None of the sectors ana- 

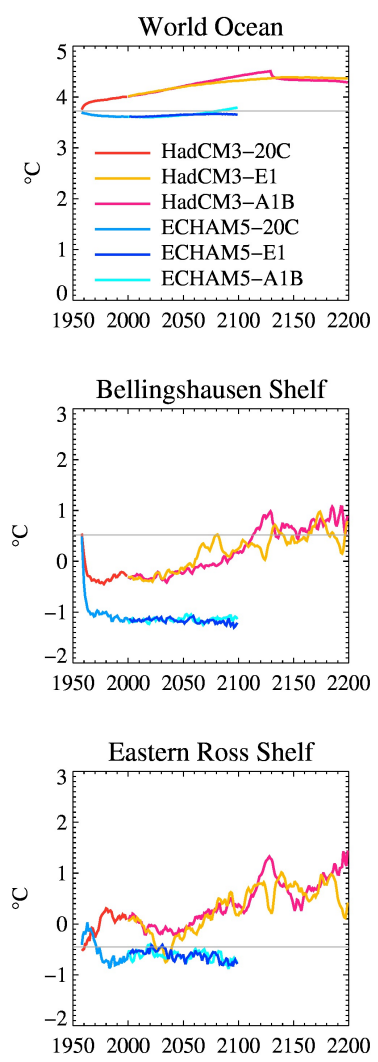
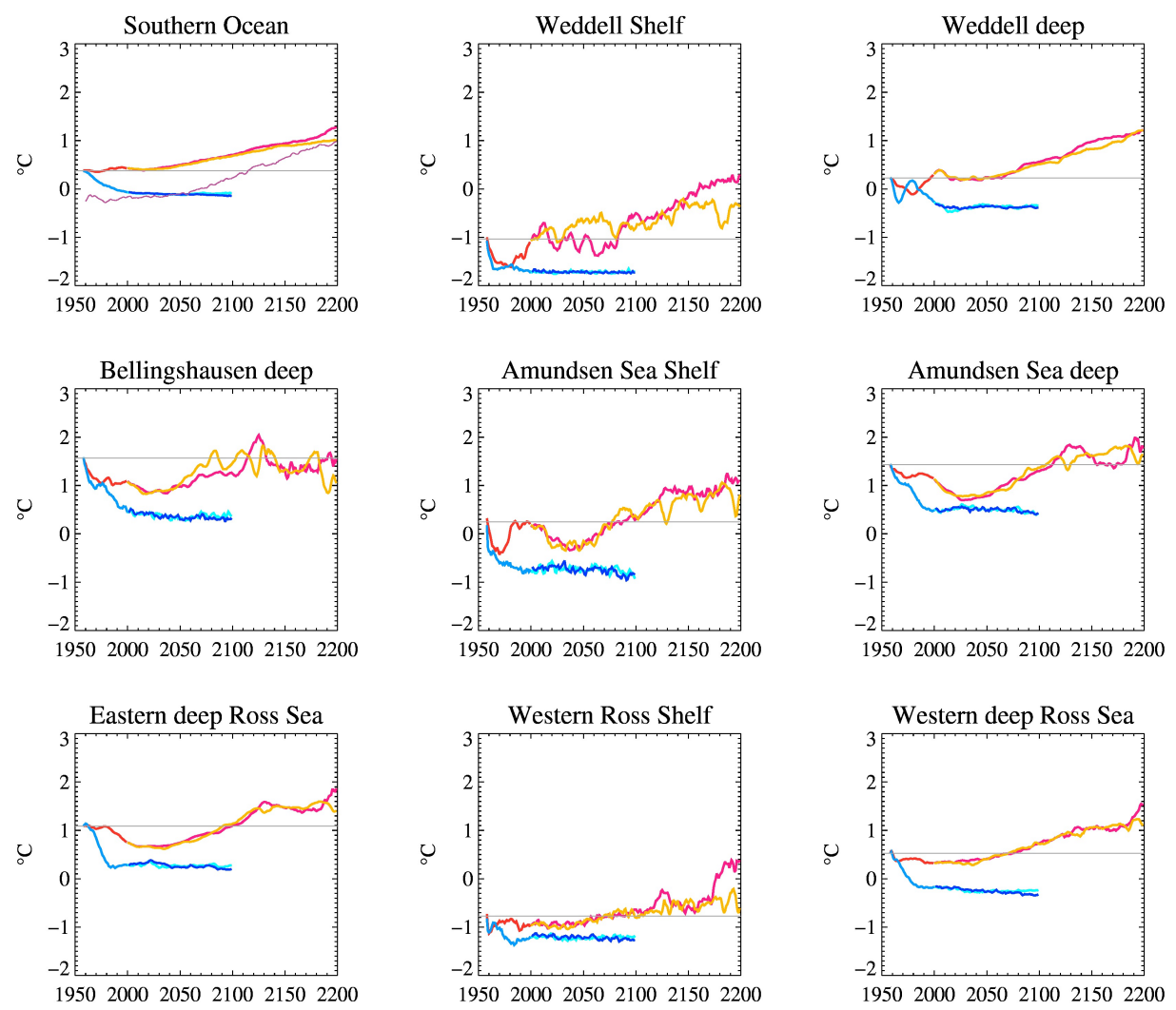

Fig. 4 Global and sector-wide averages of potential temperature. See Fig. 3 for definition of sectors. Boundaries between "shelf" and "deep" sectors are along the 800-m isobath in the Weddell and Amundsen Seas and along the 700-m isobath in the other sectors. Surface waters are excluded. For comparison, a magenta line denoting the mean temperature in the Arctic (north of $67^{\circ} \mathrm{S}$ ) in the HadCM3-20C/A1B simulation has been added to the "Southern Ocean" panel. The grey horizontal lines indicate the mean temperatures derived from NOAA's World Ocean Atlas 2001, which serves as a common inital state for all simulations.

lyzed shows a warming trend during the 21st century in these simulations, and neither does the global mean.

In contrast, simulations forced with HadCM3 show a substantial warming for all sectors, with the A1B scenario being only slightly warmer than E1. Warming in the Southern Ocean and particulary in the Arctic Ocean (magenta line in the Southern Ocean panel in Fig. 4) over the 21st and 22nd centuries exceeds warming of the global ocean by more than a factor of two.

While the circumpolar Southern Ocean mean temperature in the HadCM3 simulations features an almost uniform increase over the 21st and 22nd centuries, sector-wide averages partly show a different behaviour. After some initial adjustment in the 20th century (cooling by convection, then partial replenishment with warmer water entering the shelf), mean temperatures in the Weddell Shelf sector from the HadCM320C/E1/A1B simulations remain largely constant and close to the observed present-day state during the 21 st century, albeit with a substantial amount of interannual variability. Episodic warm pulses in the first half of the 21st century originating from warmer water in the deep Weddell Sea are prominent in the HadCM3A1B scenario; they reach into Filchner-Ronne Ice Shelf cavity and cause a rapid increase in ice shelf basal melting (Section 3.5). Mean temperature of the warm water in the deep Weddell Sea shows strong initial variations but then remains constant (and close to the observed present-day value) until about 2065 (i.e., also during the period of warm pulses onto the Weddell Sea continental shelf), after which a persistent warming of about $1^{\circ} \mathrm{C} /$ decade starts.

The Bellingshausen Sea in the HadCM320C/E1/A1B experiments shows a similar behaviour with little warming until about 2050 and a trend of about $1^{\circ} \mathrm{C} /$ decade thereafter. The Amundsen Sea shelf and deep sector show substantial variations with a cold regime during the first half of the 21st century and persistent warming again after 2050. Compared to present-day observations, both seas feature a cold bias of $0.5-0.8^{\circ} \mathrm{C}$ during large parts of the 20 th and 21 st centuries. 
While the Eastern Deep Ross Sea sector in the HadCM3-20C simulation features a cold bias similar to the Amundsen and Bellingshausen Seas, the Eastern Ross Sea Shelf is too warm. Both eastern sectors show a persistent warming in the HadCM3-E1/A1B simulations after 2050. For the western Ross Sea sectors, 20thcentury mean temperatures are close to contemporary observations and warming is considerably delayed due to the cooling effect (thermal buffering) of the Ross Ice Shelf.

As already mentioned, simulations with ECHAM520C feature a distinct cold bias for all Southern Ocean sectors. Trends over the 21st century derived from ECHAM5-E1/A1B projetions are small but always negative.

\subsection{Ocean salinity}

The analysis of mean salinities and surface salt fluxes sheds light on the reasons for the different behaviours of mean temperature discussed in the previous section. As already mentioned, the global mean surface salt flux in the open ocean is enforced to be zero as part of the coupling scheme; the small negative trend for the global mean model salinity (top left panel in Fig. 5) thus reflects the combined effects of the unbalanced freshwater input from ice shelf basal melt water and of numerical inaccuracies accumulated over the $4.2 \cdot 10^{7}$ time steps necessary for a 1958-2199 simulation.

A common feature for Southern Ocean sector mean salinities in our simulations is a negative trend that is usually small in the 21st century but becomes strong after 2100 (Fig. 5). In most cases the acceleration of freshening in the 22nd century appears to be a response to increasing ice shelf meltwater input (Section 3.5), so that it must be regarded as part of the system's response rather than an aspect of model forcing. The Weddell Shelf sector stands out as the only region with a substantial negative trend (about -0.2 per decade) in salinity already in the 21 st century.

For the deep sectors, differences between ECHAM5 and HadCM3 forcing are small. In all simulations, salinities stay close to the observed present-day values with a trend of typically -0.05 per century until 2100 . As already mentioned, the freshening accelerates in the $22 \mathrm{nd}$ century, with the A1B scenario showing a substantially stronger response than E1.

In contrast, all shelf sectors in the simulation with ECHAM5-20C forcing show a pronounced salty bias compared to present-day observations. All trends towards a freshening of the continental shelf in the ECHAM5-E1/A1B experiments thus start from a sub- stantially more salty regime. For the Weddell Shelf sector, present-day (observed) salinities in these experiments are reached at about 2070 (with little difference between E1 and A1B); in all other sectors mean salinities on the shelf remain higher by about 0.2 than the present-day values until the end of the 21 st century (i.e., the end of the simulation). In the Western Ross Shelf sector, salinity in the ECHAM5-20C/E1/A1B simulations increases to 35.3 by 1970 and continues to rise throughout the 21st century. Compared to this, the FESOM simulations with HadCM3-20C forcing are closer to present-day observations, with a slight tendency towards being fresher.

\subsection{Surface heat and freshwater fluxes}

The pronounced salinity offset between the ECHAM5 and HadCM3 simulations can be explained by an analysis of the ocean surface freshwater fluxes, which are dominated by the salt enrichment due to the formation and export of sea ice, which in turn is forced by the surface heat budget. Time series of surface heat and freshwater fluxes on the Antarctic continental shelves in simulations forced with HadCM3-20C/A1B and ECHAM5-20C/A1B output reveal strong differences between the two models for present-day climate already. Averaged over the open ocean south of $50^{\circ} \mathrm{S}$ and over 1990-1999, we find upward surface heat fluxes of $12.5 \mathrm{~W} / \mathrm{m}^{2}$ and $17.8 \mathrm{~W} / \mathrm{m}^{2}$ for HadCM3-20C and ECHAM5-20C, respectively. The difference increases to 21.1 vs. $32.9 \mathrm{~W} / \mathrm{m}^{2}$ if the area is restricted to the region south of $65^{\circ} \mathrm{S}$. For the Antarctic continental shelf, which we define as the area south of $68^{\circ} \mathrm{S}$ and shallower than $800 \mathrm{~m}$ (excluding ice shelves), we find upward surface heat fluxes of $43.3 \mathrm{~W} / \mathrm{m}^{2}$ for HadCM3-20C and 75.7 W/m² for ECHAM5-20C.

The differences between the modeled surface heat fluxes obviously reflect differences in the atmospheric forcing fields. In the open ocean far away from the coast, mean near-surface temperatures are very similar. However, results from ECHAM5 are about $1{ }^{\circ} \mathrm{C}$ colder than those from HadCM3 in the central Ross and Weddell Seas. Towards the coast, the difference increases to 3$4{ }^{\circ} \mathrm{C}$. Both models suggest a substantial temperature increase during the 21st century, but again HadCM3 is warmer with a trend of $4^{\circ} \mathrm{C}$ per decade as apposed to $3{ }^{\circ} \mathrm{C}$ per decade in ECHAM5. As a consequence, ECHAM5 temperatures near the Antarctic coast at the end of the 21st century are still slightly colder than the present-day temperatures in HadCM3.

Shortwave radiation over the Southern Ocean decreases during the 21st century due to an increase in cloud coverage in both climate models, but the trend is 

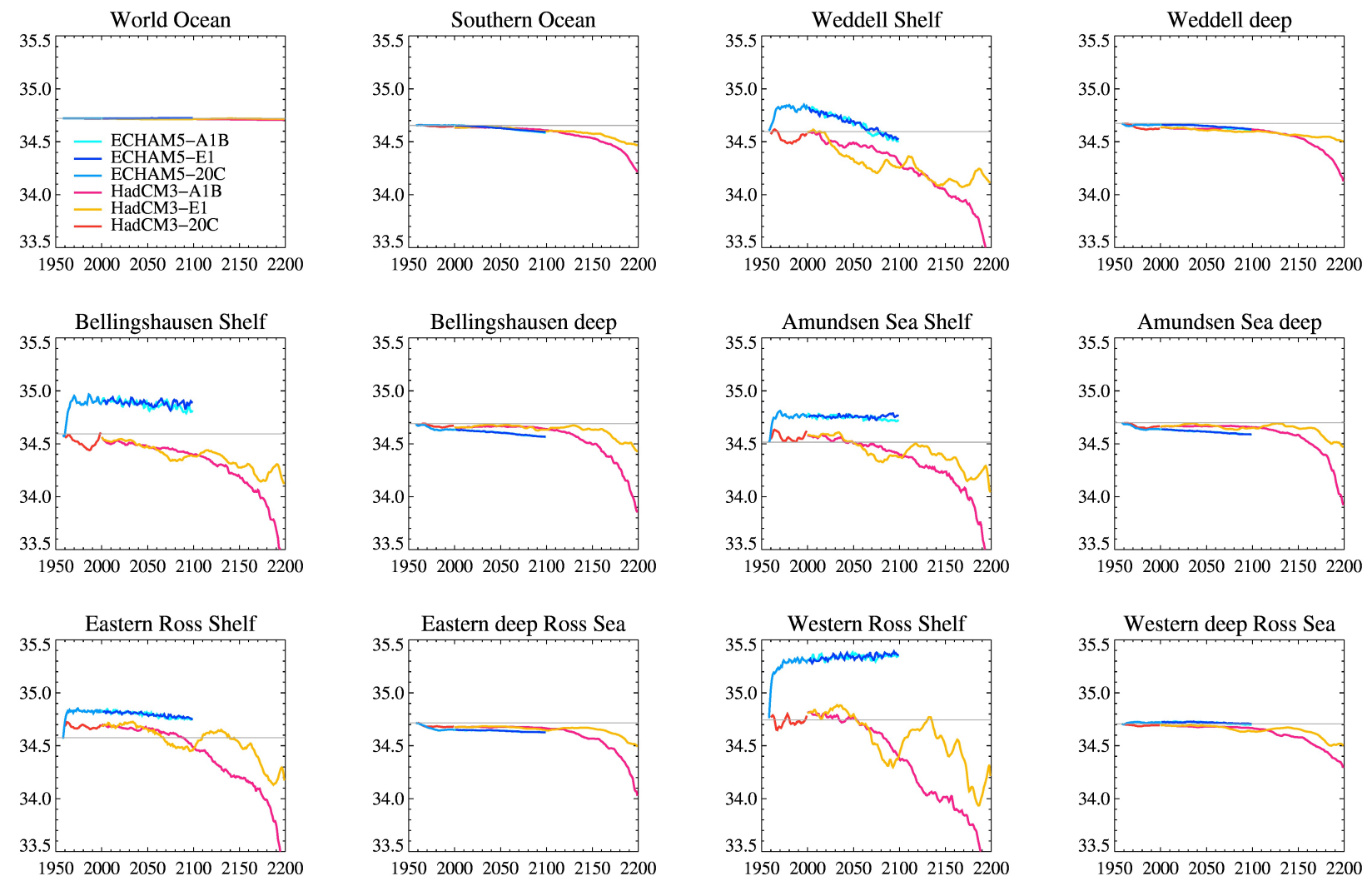

Fig. 5 Global and sector-wide averages of simulated salinity. See Fig. 3 for definition of sectors. The grey horizontal lines indicate the mean salinities derived from NOAA's World Ocean Atlas 2001, which serves as a common inital state for all simulations.

much stronger in ECHAM5, compensating for a large part of the projected near-surface warming. Downward longwave radiation is stronger in ECHAM5 than in HadCM3, but the difference (typically about $10 \mathrm{~W} / \mathrm{m}^{2}$ in the marginal seas) is too small to compensate for the bias induced by the other fields.

While the small differences in net heat flux averaged over the whole Southern Ocean are consistent with the similarity of total ice volumes in the HadCM3 and ECHAM5 simulations (see Fig. 2), the intensification of heat loss over the continental shelf areas leads to much higher net freezing rates in simulations forced with ECHAM5 output. For the continental shelf as defined above, we find net sea ice productions of $3.8 \mathrm{~m} / \mathrm{yr}$ for 1990-1999 in HadCM3-20C and $5.6 \mathrm{~m} / \mathrm{yr}$ in ECHAM5-20C. In addition, precipitation for this region is stronger in HadCM3 than in ECHAM5 (0.90 m/yr vs. $0.42 \mathrm{~m} / \mathrm{yr})$, while evaporation is nearly identical (0.11 m/yr vs. $0.10 \mathrm{~m} / \mathrm{yr}$; all for 1990-1999). As a result, the net surface freshwater flux (which is always upward in annual means for this area) is much larger in simulations forced with ECHAM5 data (Fig. 6). Stronger salt input leads to intensified convection, quickly eroding any heat provided by subsurface intrusions of warm water and keeping the water column well mixed with a temperature near the surface freezing point.

For the 21st century in the ECHAM5-A1B experiment, only a small trend towards a decreasing freshwater loss exists (1.3 mm/ $\mathrm{yr}^{2}$ for 2000-2099). In HadCM3$\mathrm{A} 1 \mathrm{~B}$, the combined signal of reduced sea ice formation and increasing precipitation is much stronger with $2.1 \mathrm{~mm} / \mathrm{yr}^{2}$ for $2000-2099$ and $3.9 \mathrm{~mm} / \mathrm{yr}^{2}$ for 2000 2199 (Fig. 6). Therefore, net growth rates and net freshwater loss with ECHAM5-A1B forcing even at the end of the 21st century are still much higher than presentday values with HadCM3.

To summarize the analysis of Southern Ocean hydrography in our model, we find that FESOM simulations forced with ECHAM5 output differ from the HadCM3 experiments by a stronger heat loss over the Antarctic continental shelf. This leads to higher sea ice formation rates, which (together with a smaller contribution from precipitation differences) results in a stronger salinification and a cold, salty bias of the water column on the continental shelf in these simulations. The production of High Salinity Shelf Water intensifies the barrier effect of the continental slope front (Jacobs, 

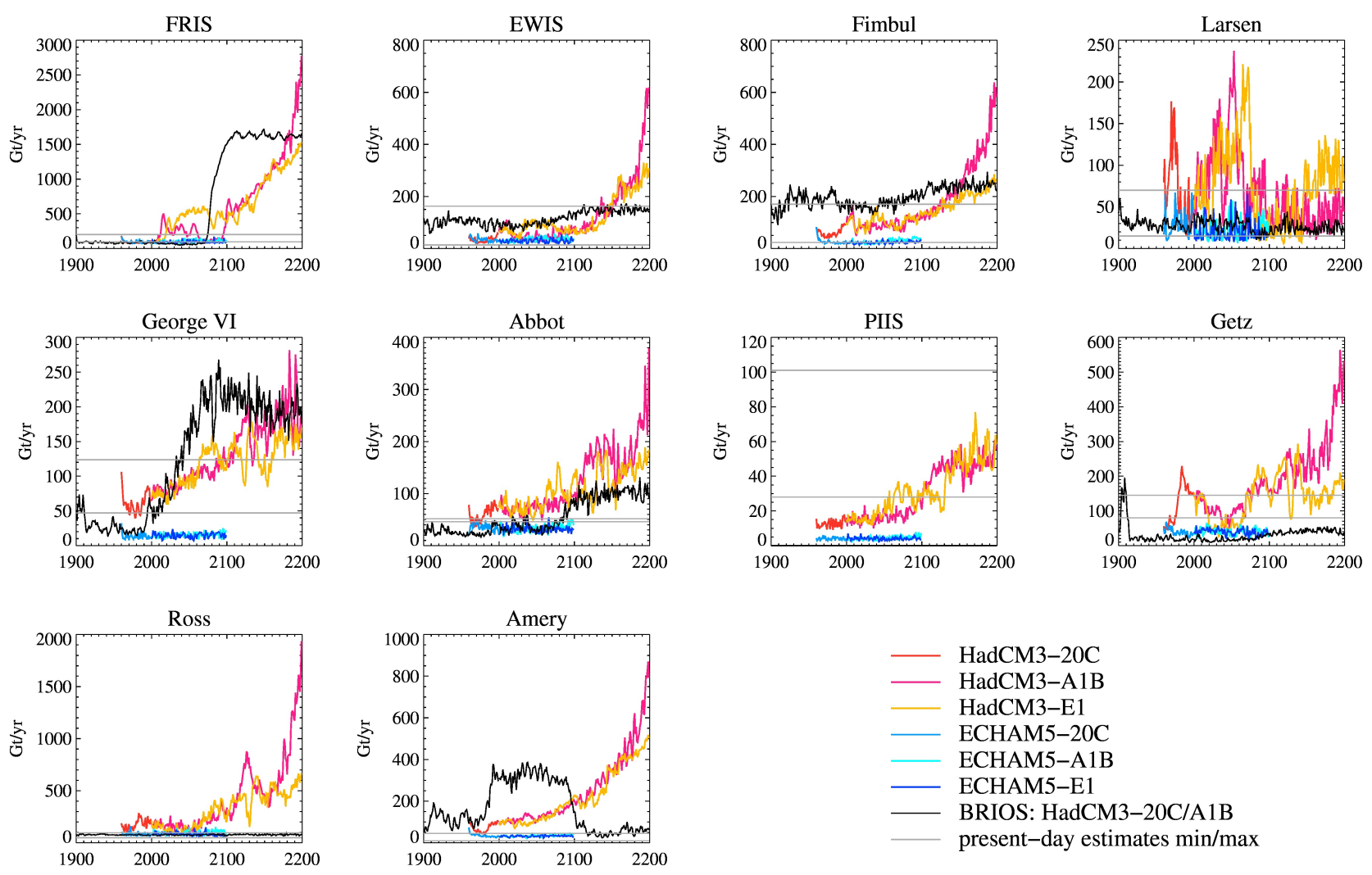

Fig. 7 Annual means of ice shelf basal mass loss (Gt/yr) in the Weddell Sea (top row), Amundsen/Bellingshausen Seas (middle row) and for Ross and Amery Ice Shelves (bottom row). Note the varying y-axis range. All FESOM simulations start in 1958: the first two years are heavily biased due to initial adjustment processes and are not displayed. In addition to the suite of FESOM simulations (colored lines), time series from a HadCM3-20C/A1B simulation with BRIOS (Hellmer et al., 2012) are given as black lines. Grey lines indicate the range of independent estimates for present-day melt rates (compiled in TWH12, updated with data from Rignot et al., 2013). EWIS = Eastern Weddell Ice Shelves (Brunt and Riiser-Larsen Ice Shelves).

1991), so that warmer water of deep ocean origin cannot reach onto the shelf in these simulations.

Output from HadCM3, in comparison, suggests a more moderate heat loss and a higher precipitation rate over the continental shelf, which implies less salt input and less convection in this area. Salinities in presentday simulations with this forcing are rather realistic. Freshening trends arising mainly from decreasing sea ice formation lead to a reduction of the shelf water density, allowing for warm deep water intrusions in the 21st/22nd centuries in these simulations.

It may seem surprising that sea ice volume is not (substantially) affected by the inter-model differences in heat flux and sea ice production on the continental shelf (Fig. 2). This is mainly due to the fact that vertical ('conductive') heat flux through sea ice quickly decreases with increasing ice thickness, which immediately reduces sea ice growth rates. Higher sea ice production on the continental shelf implies that the ice exported northward is thicker and more compact, so that growth rates in the deep open ocean are conversely re- duced and a very similar maximum thickness is reached. Given that maximum sea ice extent is limited by the location of the Antarctic Circumpolar Current, which is very similar in all experiments, total sea ice volume proves to be rather insensitive towards different distributions of surface heat flux.

\subsection{Ice Shelves}

Consistent with the variations of ocean heat and salt content discussed in the previous sections, time series of ice shelf basal melting (Fig. 7) vary strongly between the forcing models employed. This is already true for the simulations of present-day, which show consistently lower melt rates for all ice shelves if data from ECHAM5-20C are used. None of the ECHAM5 simulations for the 21st century show a significant trend in basal melting for any of the ice shelves, while experiments forced with HadCM3 output suggest a substantially increased basal mass loss. Compared to the dif- 

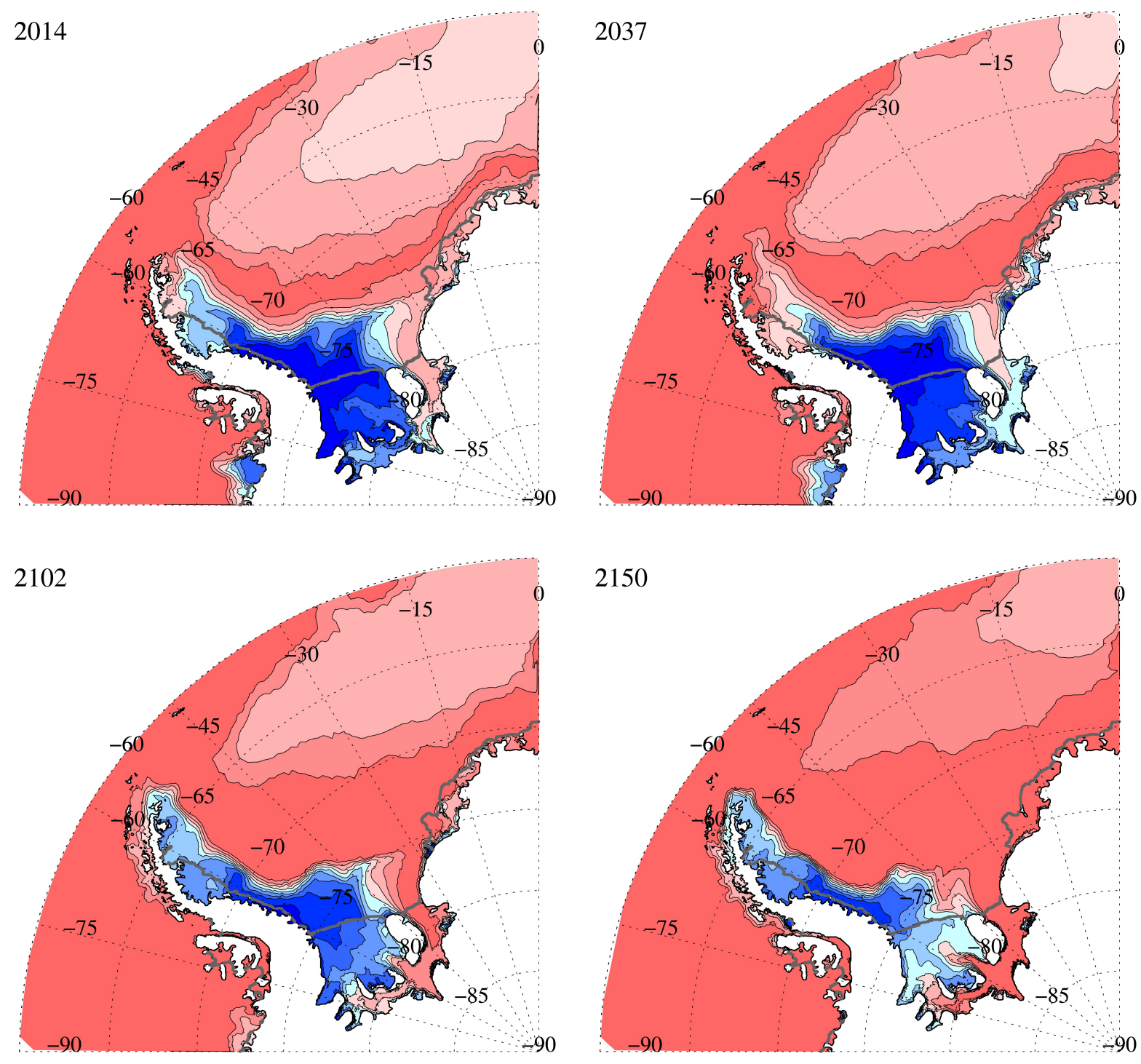

$\begin{array}{lllllllllll}-2.0 & -1.8 & -1.6 & -1.4 & -1.2 & -1.0 & -0.8 & -0.6 & -0.4 & -0.2 & 0.0\end{array}$

Fig. 8 Simulated near-bottom temperature (annual means) in the Weddell Sea for 2014, 2037, 2101, and 2150 in the FESOM simulation forced with HadCM3-A1B data.

ference between forcing models, the difference between scenarios is small.

\subsubsection{Filchner-Ronne Ice Shelf}

Based mostly on experiments with the circumpolar BRIOS model and supported by results from the FESOM HadCM3-A1B simulation, Hellmer et al. (2012) proposed the potential of a rapid and dramatic increase of basal melt rates for Filchner-Ronne Ice Shelf (FRIS). With the suite of FESOM simulations completed, we are now able to analyse the model response for a wider range of forcing scenarios.
For the present-day situation, FESOM simulations with ECHAM5-20C and HadCM3-20C forcing yield very similar melt rates of about $90 \mathrm{Gt} / \mathrm{yr}$, which compares well to the estimates of Joughin and Padman (2003). Projections for the 21st century with ECHAM5 output yield an increase to $110 \mathrm{Gt} / \mathrm{yr}$ for the A1B scenario and no trend at all for E1.

When forced with HadCM3-A1B data, the pulses of warm water discussed in Section 3.2 lead to an episodic increase of basal melting to 300-500 Gt/yr for three consecutive events centered at 2015, 2037, and 2057. For the period 2065-2095, melt rates decrease to presentday values. From 2095 onwards, basal mass loss in- 


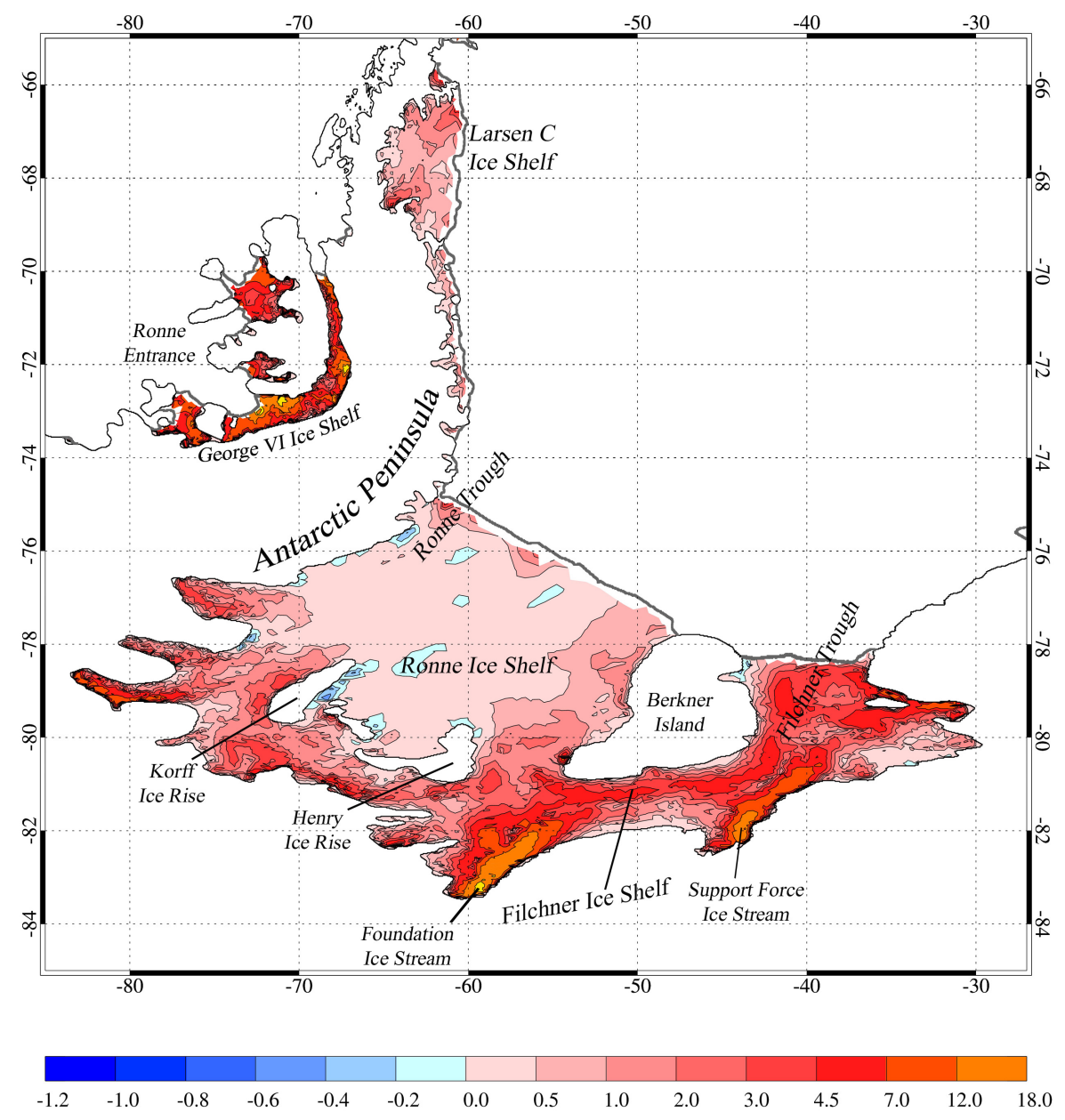

Fig. 9 Basal melt rates $(\mathrm{m} / \mathrm{yr}$ ) for Filchner-Ronne, Larsen C, and George VI Ice Shelves during the 22nd century in a simulation forced with HadCM3-A1B data (ten-year average 2140-2149). Note the non-linear color scale.

creases to an average of $600 \mathrm{Gt} / \mathrm{yr}$ (corresponding to a mean melt rate of $1.8 \mathrm{~m} / \mathrm{yr}$ ) for the period $2100-$ 2130 , and then continues to rise reaching $980 \mathrm{Gt} / \mathrm{yr}$ in 2150 and $2300 \mathrm{Gt} / \mathrm{yr}$ as an average for 2190-2199. For HadCM3-E1, the first two warm events occur about ten years later than for HadCM3-A1B, but instead of returning to present-day melt rates in the second half of the 21st century, basal mass loss remains mostly between 400 and $600 \mathrm{Gt} / \mathrm{yr}$ until 2100. Acceleration of basal melting after 2100 occurs in a way similar to HadCM3-A1B, but the decadal mean for 2190-2199 does not exceed $1500 \mathrm{Gt} / \mathrm{yr}$.

Weddell Sea near-bottom temperatures in the FESOM HadCM3-A1B simulation (Fig. 8) show a behaviour similar to the evolution in the corresponding BRIOS experiment. In both models, pulses of warm water are found on the shelf during the first half of the 21st century. In BRIOS, dissipation limits their extent to the northern Filchner Trough (see map in Fig. 9), so that ice shelf basal melting is not yet affected at this stage. In FESOM, owing to the higher resolution (about $10 \mathrm{~km}$ in the region discussed here), these pulses reach the interior of the FRIS cavity (panels 2014 and 2037 in Fig. 8) with little dilution and thus cause an earlier, albeit episodic increase in basal mass loss. Also similar to the BRIOS results, although about 20 years later, the period of intermittent warming and cooling is followed by an unreversed destruction of the Antarctic slope front, after which a tongue of only slightly modified Warm Deep Water reaches deep into the Filchner Ice Shelf cavity and enters Ronne Ice Shelf cavity near the grounding line south of Berkner Island (panel 2102 in Fig. 8). 

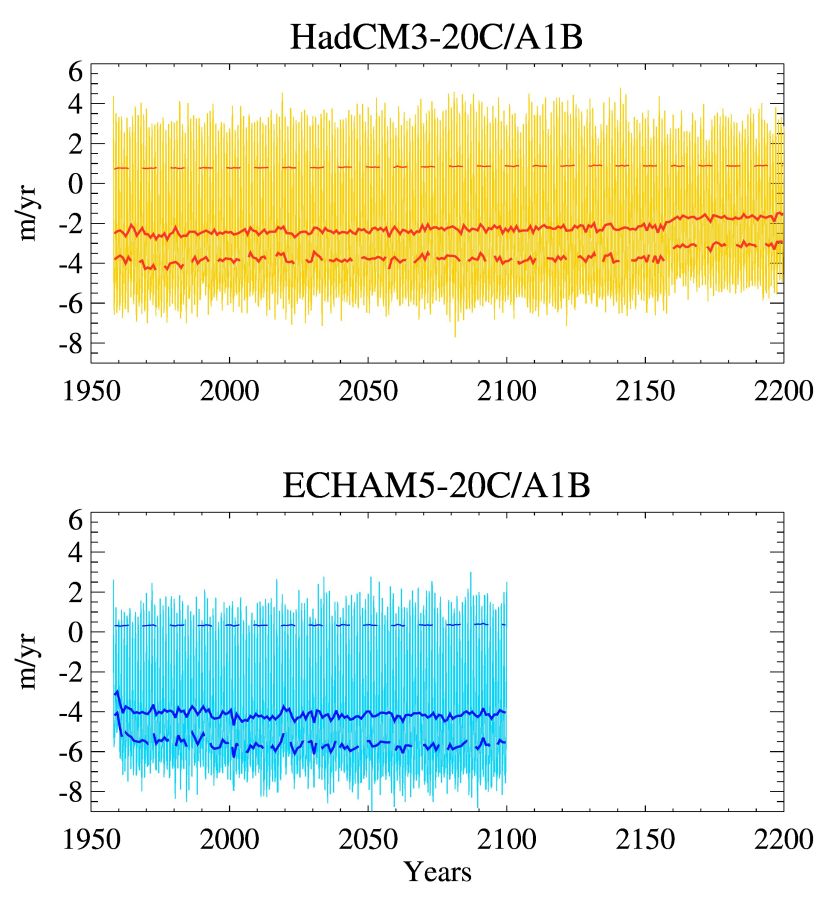

Fig. 6 Surface freshwater flux on the Antarctic continental shelf in simulations forced with HadCM3-20C/A1B (top) and ECHAM5-20C/A1B (bottom) output. Thin, light lines represent monthly mean values of net freshwater flux and thus indicate seasonal minima and maxima; thick, dark solid lines show the annual means. Thin dashed lines indicate annual means of net precipitation; thick dashed lines show annual mean sea ice net growth rates (in $m$ ice per year). All fluxes have been averaged over the area south of $68^{\circ} \mathrm{S}$ and shallower than $800 \mathrm{~m}$, excluding ice shelf cavities. Negative values represent freshwater extracted from the ocean.

In contrast to BRIOS, where the water properties off the continental shelf change very little, this process in FESOM is accompanied with a gradual warming of the upper 1000-m water column (as has been discussed in Section 3.2). Melt rates in FESOM thus do not assume a new steady state $(1600 \mathrm{Gt} / \mathrm{yr}$ for most of the $22 \mathrm{nd}$ century in the BRIOS HadCM3-A1B simulation) but continue to rise until the end of the simulation. We attribute this difference in behaviour to the fact that FESOM is a global model with no restoring at any open boundary, so that it can react more freely to long-term changes in the forcing fields and thus deviates further from the initial state.

The distribution of FRIS basal melt rates in the middle of the 22nd century of the FESOM HadCM3A1B simulation (Fig. 9) largely resembles the presentday pattern (see TWH12), although with very different amplitudes. Maximum melt rates of about $18 \mathrm{~m} / \mathrm{yr}$ occur near the grounding lines of Support Force and Foundation ice streams in the deepest (southernmost) parts of the cavity. Here, the ice base extends down to more than $1200 \mathrm{~m}$ below sea level and the in situ freezing point is $0.9 \mathrm{~K}$ below the surface freezing point. Marine ice still forms at rates of up to $0.6 \mathrm{~m} / \mathrm{yr}$ north of the Henry and Korff Ice Rises. Compared to the BRIOS simulation of Hellmer et al. (2012), maximum melt rates are smaller, but strongly increased melt rates are found for a larger area.

\subsubsection{Eastern Weddell Sea}

For Brunt and Riiser-Larsen Ice Shelves in the eastern Weddell Sea, and also for Fimbulisen, melt rates in FESOM simulations with ECHAM5-20C and HadCM3$20 \mathrm{C}$ are on the small side of the range of independent estimates for present-day melt rates (with Rignot et al., 2013, setting the lower boundary). Basal mass loss in the 21st century in FESOM HadCM3-E1/A1B experiments increases by a factor of three for these ice shelves, but still remains within the range of presentday estimates. After 2100, basal mass loss starts to increase rapidly. In contrast, ECHAM5-E1/A1B experiments show very little deviation from their 20th century melt rates.

\subsubsection{Larsen C Ice Shelf}

Since we use the RTopo-1 ice shelf configuration, only Larsen $\mathrm{C}$ and a small remnant of Larsen B Ice Shelf are present in the FESOM setup. In contrast to all other ice shelves, Larsen Ice Shelf in FESOM HadCM3-A1B/E1 simulations shows a significant increase of melt rates in the 21st century, but then a decrease to presentday values from 2090 onward. Interannual variability is high during the entire time series and for all experiments. Both findings can be explained with the variable hydrography on the western Weddell Sea continental shelf: While water originating from the Filchner/Berkner shelf has a temperature close to the surface freezing point, modified Warm Deep Water with temperatures up to $-0.5^{\circ} \mathrm{C}$ enters the Larsen continental shelf (Fig. 8) and the Larsen Ice Shelf cavity episodically, always leading to increased basal melt rates. Towards the end of the 21st / beginning of the 22nd century, melt rates at FRIS increase to about $600 \mathrm{Gt} / \mathrm{yr}$ in HadCM3-E1/A1B. The related freshwater input reduces the density of water on the southern Weddell Sea continental shelf to an extent that suppresses the formation of deep and bottom water from this source. Instead, the now lighter shelf water remains at shallower depths providing a steady supply of cold water for the western shelf and reducing Larsen Ice Shelf basal melt rates to the low present-day values.

FESOM simulations with ECHAM5-20C/E1/A1B forcing show very little decadal variability and no trend 
towards increasing melt rates. Interannual variability is high in these simulations as well, which indicates that the variable hydrography in this region is a robust feature independent of the forcing applied.

\subsection{Amundsen and Bellingshausen Seas}

\subsubsection{George VI Ice Shelf}

For George VI Ice Shelf, the FESOM simulation with HadCM3-20C forcing suggests a mean mass loss of 60 Gt/yr (mean melt rate of $3.5 \mathrm{~m} / \mathrm{yr}$ ), which is well within the range of observation- and model-based estimates of Potter and Paren (1985), Jenkins and Jacobs (2008), Holland et al. (2010), and Rignot et al. (2013). While melt rates in the FESOM ECHAM520C/E1/A1B simulations remain below present-day values even in the 21st century, an increase to about $160 \mathrm{Gt} / \mathrm{yr}$ (200 Gt/yr) is suggested in the HadCM3-E1 (A1B) simulations.

The BRIOS simulation with HadCM3-20C/A1B forcing shows low melt rates for the 20th century followed by a rapid increase between 1990 and 2070, while FESOM suggests a more gradual, steady increase over the 21st and 22nd centuries. Melt rates at the end of the A1B scenario are very similar between the two ocean models.

\subsubsection{Abbot Ice Shelf}

Compared to the estimate of Rignot et al. (2013), simulated present-day basal melting of Abbot Ice Shelf (70 Gt/yr as an average for 1980-1999) is on the high side for the FESOM HadCM3-20C simulation, and on the low side for FESOM ECHAM5-20C and BRIOS HadCM3-20C experiments (34 and $32 \mathrm{Gt} / \mathrm{yr}$, respectively). BRIOS and FESOM simulations with HadCM3-A1B forcing agree in that they suggest only little increase in basal melting during the 21st century, followed by a larger trend in the 22nd century.

\subsubsection{Pine Island Ice Shelf}

Although the FESOM model considers the Jenkins et al. (2010) cavity geometry and despite a resolution of $4 \mathrm{~km}$ in the cavity and the open ocean near the ice front, modeled basal melt rates for Pine Island Ice Shelf (PIIS) in present-day climate remain well below observationbased estimates of, e.g., Jacobs et al. (1996, 2011a) and Rignot et al. (2013). We attribute this deficiency to a cold bias in Amundsen Sea shelf and slope waters (c.f. Fig. 4), caused by an overestimation of convection triggered by sea ice formation in this area. For NCEP reanalysis data, a cold bias for the Amundsen Sea embayment was demonstrated by Assmann et al. (2005); it may most likely be due to the fact that horizontal resolution of the reanalysis model is coarse compared to the size of the bay. Given that resolution of the climate models employed in this study is even worse $\left(3.75^{\circ}\right.$ in zonal direction, $2.5^{\circ}-3.5^{\circ}$ in meridional direction) it appears reasonable to assume that a similar cold bias may occur here.

After the warming of Amundsen Sea water in the 21st and particularly in the 22nd century of FESOMHadCM3 simulations, melt rates for PIIS increase by a factor of four but still remain below $60 \mathrm{Gt} / \mathrm{yr}$ and thus do not even exceed the range of observation-based estimates for present-day melt rates.

\subsubsection{Getz Ice Shelf}

Based on the years 1994-2009, Jacobs et al. (2011b) suggest that equilibrium basal mass loss for Getz Ice Shelf may be as high as $80 \mathrm{Gt} / \mathrm{yr}$, plus a disequilibrium melting of $\approx 48 \mathrm{Gt} / \mathrm{yr}$. While FESOM forced with NCEP reanalysis data suggests an average basal mass loss of $164 \mathrm{Gt} / \mathrm{yr}$, which even exceeds the total melt rate based on these estimates (TWH12), melt rates in the FESOM ECHAM5-20C/E1/A1B simulations remain below the lower limit.

Following the evolution of Amundsen Sea mean shelf water temperature (Fig. 4), FESOM HadCM3$20 \mathrm{C} / \mathrm{A} 1 \mathrm{~B}$ suggest a rapid warming in the 20th century, followed by gradual cooling over the next six decades both are probably due to a model adjustment process rather than a climate signal. Starting 2040, basal melting increases to an average of $420 \mathrm{Gt} / \mathrm{yr}$ for the last decade of the 22nd century. Forced with HadCM3-E1 data, basal melt rates largely follow the A1B time series until about 2140, after which they show no further increase and remain between 100 and $200 \mathrm{Gt} / \mathrm{yr}$.

BRIOS melt rates for Getz Ice Shelf are consistently too low and show little variation; this small ice shelf is clearly beyond the scope of such coarse-resolution model.

\subsection{Ross Ice Shelf}

For Ross Ice Shelf, basal melt rates in the FESOM ECHAM5-20C simulation closely matches the $81 \mathrm{Gt} / \mathrm{yr}$ suggested by Jacobs et al. (1992), while the HadCM320C experiment exceeds this estimate by a factor of two. FESOM evaluation experiments with NCEP forcing (TWH12) have identified two areas of spuriously high melting east of Roosevelt Island and south of Ross Island; together with an intense summer melting near 
the ice front in years with an anomalously low summer sea ice coverage, these areas contribute about $40 \%$ to the total basal mass loss.

In contrast to BRIOS and to the FESOM ECHAM520C/E1/A1B simulations, which all suggest no trend at all for Ross Ice Shelf in the 21st/22nd centuries, FESOM HadCM3-A1B/E1 experiments propose a steady increase of melt rates after 2050. By 2150, basal mass loss exceeds $500 \mathrm{Gt} / \mathrm{yr}$; it rises to $600 \mathrm{Gt} / \mathrm{yr}$ (1500 Gt/yr) for the last decade of the 22nd century in the E1 (A1B) scenario. The cooling effect of the ice shelf delays warming for the western Ross shelf sector considerably (Fig 4).

\subsection{Amery Ice Shelf}

The comparison of basal melt rates between different simulations with the BRIOS and FESOM models suggests that Amery Ice Shelf is very sensitive to surface boundary conditions over the continental shelf near the ice front. Melt rates in the BRIOS HadCM3-A1B experiment are peculiar in that they rise from 100 to 350 Gt/yr during the 21st century and then drop to even below their 20th century values after 2090 .

FESOM melt rates with NCEP forcing have been found to be excessively high $(174 \mathrm{Gt} / \mathrm{yr}$, which is much higher than any previous estimate; see TWH12). Mean melt rate in the FESOM ECHAM5-20C simulation is only $30 \mathrm{Gt} / \mathrm{yr}$, which is close to the centre of the range of independent estimates compiled in TWH12. The mean basal mass loss of $80 \mathrm{Gt} / \mathrm{yr}$ proposed by the FESOM HadCM3-20C experiment is at the upper end of the range but still reasonable; it increases to about $200 \mathrm{Gt} / \mathrm{yr}$ for 2100 and to $500 \mathrm{Gt} / \mathrm{yr}(800 \mathrm{Gt} / \mathrm{yr})$ at the end of the 22nd century in the E1 (A1B) scenario.

\section{Discussion and Conclusions}

We presented results from a global finite-element sea ice - ice shelf-ocean model that has been forced with atmospheric output from the climate models ECHAM5/MPI-OM and HadCM3. Sea ice concentration, ocean heat and salt contents for various sectors of the Southern Ocean, and basal melt rates for the ten larger Antarctic ice shelves have been compared to present-day observations and found to be in a good agreement in most aspects. From the end of the 20th century, projections of the IPCC scenarios E1 and A1B were applied to investigate the Southern Ocean's response to a warming climate.

We found that FESOM projections of sea ice extent and volume for the Southern Ocean strongly de- pend on the scenario chosen, while the difference originating from the use of two different climate models is small. The opposite is true for the oceanic heat and salt contents: Differences between two scenarios with the same climate model are small, while the difference between the models is huge. Even for the present-day mean state, simulations forced with ECHAM5 output differ from experiments forced with HadCM3 data by a stronger heat loss close to the Antarctic coast. This leads to higher sea ice formation rates, a stronger salinification, increased convection, and a cold, salty bias of the water column on the continental shelf. Warmer water from the deep ocean cannot penetrate into the sub-ice cavities in these simulations. Consequently, the ECHAM5 experiments show no significant trend in ice shelf basal melting for the E1 and A1B scenarios.

Compared to this, simulations with HadCM3 output suggest a smaller heat loss (and a higher precipitation) over the continental shelf, which implies less salt input and less convection in this area. A freshening trend arising from decreasing sea ice formation reduces salinity on the shelf even further, allowing for Warm Deep Water to reach far into the sub-ice cavities, causing a substantial increase of ice shelf basal mass loss during the 21 st/22nd centuries.

For many of the ice shelves, the increase of basal melt rates in the HadCM3-E1/A1B simulations accelerates with time. This reflects a potentially realistic positive feedback: Increased ice shelf melting leads to a freshening of the continental shelf water, increasing stability of the water column and suppressing convection. ${ }^{1}$ Reduced convection leads to a reduced erosion of Warm Deep Water when it enters the continental shelf; what we know as Modified Warm Deep Water may become more and more unmodified. The temperature of water entering the cavity will rise (even if the source water mass remains unmodified), increasing basal melt rates even further. Such feedback is evident in the BRIOS HadCM3-A1B simulation published by Hellmer et al. (2012), but it seems at work also in FESOM and may explain the accelerated basal mass loss increase during the 22nd century. The latter is found specifically for those ice shelves that fringe a continental shelf where strong sea ice formation regularly leads to deep convection - namely all the ice shelves in the Weddell Sea, plus Ross and Amery Ice Shelves. The ice shelves in the Amundsen and Bellingshausen Seas, in contrast, are all located in areas where sea ice formation rates are small and deep convection is rare.

1 Hellmer (2004) came to a conclusion consistent with this statement when he discussed the effect of switching on and off ice shelf - ocean interaction in BRIOS. 

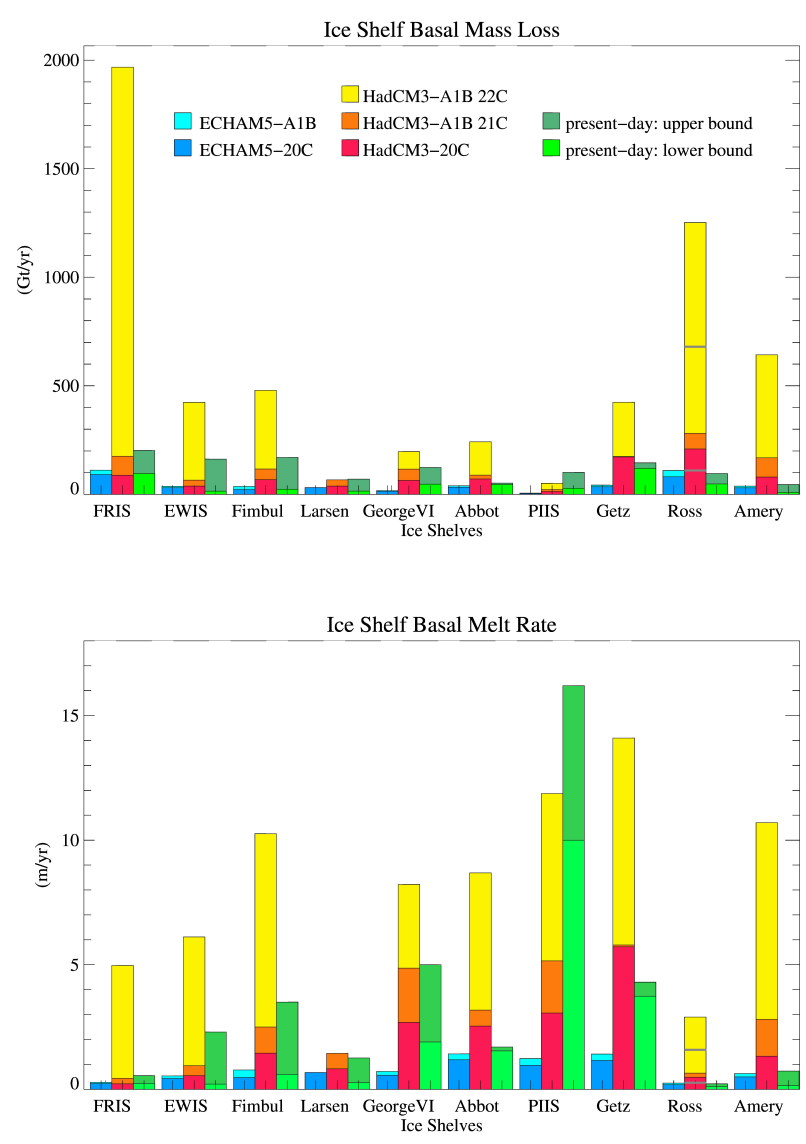

Fig. 10 Projections of twenty-year mean mass loss (Gt/yr, top panel) and basal melt rates (m/yr, lower panel). Blue columns indicate results from the FESOM simulations forced with ECHAM5-20C/A1B averaged over 1980-1999 (lower part) and 2080-2099 (upper part). Reddish columns (in the middle) give results with HadCM3-20C/A1B averaged over 1980-1999 (lower part), 2080-2099 (middle part) and 21802199 (upper part). For the green columns, the two sections indicate the lower and upper limit of the range of available estimates for present-day melt rates (TWH12, updated with data from Rignot et al., 2013). The grey lines in the HadCM3$20 \mathrm{C}$ and $22 \mathrm{C}$ columns for Ross Ice Shelf indicate average values excluding the areas of spuriously high summer melting along the western and eastern margins of the ice shelf.

From all ice shelves in this study, Filcher-Ronne Ice Shelf stands out by the prominent flushing event that increases basal melt rates from 90 to $600 \mathrm{Gt} / \mathrm{yr}$ in a first step and then to $2300 \mathrm{Gt} / \mathrm{yr}$ by the end of $22 \mathrm{nd}$ century in the HadCM3-A1B scenario - which would make this ice shelf the largest contributor of glacial melt water to the Southern Ocean at that time (Fig. 10, top). While the basal mass loss for FRIS in the 22nd century seems very high at first glance, it corresponds to melt rates ( $5 \mathrm{~m} / \mathrm{yr}$ mean, maxima around $25 \mathrm{~m} / \mathrm{yr}$ ) that are still below those commonly accepted for present-day PIIS (Fig. 10, bottom).

A very special case can be made for Larsen Ice Shelf, which in our simulations is kept safe from climate warm- ing by the strong meltwater input from Filchner-Ronne Ice Shelf. Cold, fresh water that stays on the western Weddell Sea continental shelf instead of contributing to deep water formation keeps the Larsen Ice Shelf in a cold environment even while water off the continental shelf gets continuously warmer. This appears to be an interesting aspect of ice shelf teleconnection that models focused just on one ice shelf cannot consider.

Unfortunately, the FESOM model fails to reproduce the high present-day melt rates for Pine Island Ice Shelf (PIIS). We are, however, confident that the rather moderate increase of melting in our projections for the 21st / 22nd centuries is a robust feature. Observations of Jenkins et al. (2010) show that today water of $\approx 1^{\circ} \mathrm{C}$ has access to the interior cavity. The warmest water available at the shelf break today is below $1.4^{\circ} \mathrm{C}$ at about $800 \mathrm{~m}$ depth, so that the temperature difference between water at the shelf break / slope and water flowing into the cavity is less than $0.4^{\circ} \mathrm{C}$. In contrast, water that enters the cavities of Ross and Filchner-Ronne Ice Shelves today is at the surface freezing point (about $-1.9^{\circ} \mathrm{C}$ ), while Warm Deep Water in front of the Weddell Sea continental shelf break is at about $0.5^{\circ} \mathrm{C}$. So, if we assume that the temperatures of warm deep water remain constant, the difference between water at the shelf break and water entering the cavity has a much greater potential to lead to increased melt rates for Ross and Filchner-Ronne Ice Shelves than for PIIS. Only a substantial warming of the warm deep water available at the shelf break and/or a retreat of the grounding line into deeper basins may lead to a further increase of PIIS basal melting; such warming does indeed occur in FESOM HadCM3-A1B simulations, but it has a similar magnitude for the Weddell and Amundsen Seas, so that it affects all ice shelves in a similar way. To summarize, PIIS is already floating in "warm" water, so there is only little potential to increase melt rates in a way similar to the "cold water" ice shelves.

The other large cold-water ice shelf, Ross Ice Shelf, is not affected by ocean warming in the BRIOS simulations of Hellmer et al. (2012) due to strong convection on the continental shelf that keeps the shelf water at the surface freezing point. In contrast, FESOM suggests that Ross Ice Shelf might behave similar to FRIS, although with a smaller amplitude. If we follow the discussion in TWH12, excluding the western and eastern margins of the ice shelf from the total, Ross Ice Shelf basal mass loss at the end of the 22nd century may rise to about $680 \mathrm{Gt} / \mathrm{yr}$ (grey line in Fig. 10). The large areas of the Ross and Filchner-Ronne Ice Shelves together with the huge potential of the warm water at the continental shelf break yield the possibility to turn 
them into the biggest sources of glacial melt water in the Southern Ocean by the end of the 21st century.

Given the high sensitivity found towards the different climate model realizations for identical scenarios, the question which of the two forcing datasets is more realistic and thus likely to produce more reliable projections is appropriate. Based on the material analysed in this study, however, there is no clear answer. Both forcing data sets yield a good representation of presentday sea ice cover. The seasonal cycle of sea ice formation/decay is slightly underestimated in the simulations forced with HadCM3 output due to the fact that summer ice extent is slightly too large; therefore, the salt flux due to autumn/winter sea ice formation may be too small. The weak representation of the Ross Polynya (Fig. 1) may serve as another indication for a tendency towards underestimating salt fluxes in HadCM3 experiments, but the same is not obvious for the polynyas in the southwestern Weddell Sea. On the other hand, mean ocean temperatures and salinities in the 20th century and the early 21st century in the HadCM3 simulations are close to present-day observations (with a tendency towards being too fresh), while the ECHAM5 simulations feature a pronounced cold and salty bias in many sectors of the Southern Ocean, particularly on the continental shelf (Figs. 4 and 5). Discarding any of the two suites of experiments as unrealistic is, therefore, not an appropriate choice. Instead, their results may be used as an indication of the relevant mechanisms, and their spread sheds light on the possible magnitude of the response.

Uncertainty also arises from the forcing strategy itself, i.e., forcing the ice-ocean models BRIOS and FESOM with output from two atmosphere models without any feedback. The fact that many aspects of presentday Antarctic climate are reproduced well creates some confidence in the method, but any feedback between the ocean and the atmosphere is ignored, so that the model can gradually diverge from an equilibrium state for long integrations.

Even for simulations with rapidly increasing basal melting, FESOM and BRIOS assume a fixed ice shelf geometry. While this may appear as a rather crude assumption, it should be kept in mind that the intrusion of warm water onto the continental shelf in the HadCM3-E1/A1B simulations starts with present-day ice shelf geometry. Melt rates increase considerably on a time scale that is too short to allow for a substantial change in the in-situ freezing point at the ice shelf base, so that keeping ice shelf geometry fixed at this point does not introduce substantial errors. Towards the 22nd century, when the freshwater feedback fosters accelerated melting, errors arising from a fixed ice- shelf geometry certainly increase. However, even if we assume that, e.g., the thickness of Filchner-Ronne Ice Shelf reduces to 0.5 of its current value, the temperature difference between the Modified Warm Deep Water at the continental shelf break and the in-situ freezing point near the grounding line only reduces from about 3.3 to $2.8^{\circ} \mathrm{C}$ - which still is enough to cause very high melt rates. In addition, a retreat of the grounding line is likely to increase the area with deep ice shelf draft, the effect of which - if there is any - is bound to increase rather than decrease the area-mean basal melt rate. In contrast to this, a retreat of the ice fronts by increased calving or mechanical break-up of an ice shelf with decreasing thickness will potentially decrease the area exposed to melting. For "warm water" ice shelves with basal melting being widespread, and also in case of a complete break-up, this is bound to reduce the meltwater input substantially, but for "cold water" ice shelves with melting concentrated along their grounding lines the meltwater supply will remain rather steady. We conclude that the assumption of a fixed ice shelf geometry certainly introduces substantial uncertainties to any quantitative estimate, but the representation of the underlying mechanisms and thus the characteristics of the system is still robust.

Last but not least, our results seem to contradict the findings of Kusahara and Hasumi (2013), who forced a circumpolar sea ice-ice shelf-ocean model with systematically applied idealized perturbations of the atmospheric fields. Even with a $6{ }^{\circ} \mathrm{C}$ increase of air temperature south of $60^{\circ} \mathrm{S}$, which is a signal stronger than the warming we see in the HadCM3-A1B temperature fields, the increase of basal melt rates for the giant "cold water" ice shelves in their study remains rather moderate (from 161 to $194 \mathrm{Gt} / \mathrm{yr}$ for FRIS, from 111 to 119 Gt/yr for Ross Ice Shelf). The discrepancy between their and our results can be explained, however, if we consider the sea ice formation rates. For a circumpolar area within $120 \mathrm{~km}$ from the coast, Kusahara and Hasumi (2013) report a sea ice production that converts to net growth rates of $3.3 \mathrm{~m} / \mathrm{yr}$ for present-day climate and $2.6 \mathrm{~m} / \mathrm{yr}$ for a $6^{\circ} \mathrm{C}$ warming (Kusahara, pers. comm. 2013) - which is close to what we find for this area in FESOM simulations forced with ECHAM5 data. In both cases convection is strong even for the warm scenario, so that the water column on the continental shelf is kept close to the freezing point and warm water cannot enter the cavities. We conclude that both studies consistently support the hypothesis that the salt input related to sea ice formation on the continental shelf determines water mass properties and pathways across the ice front and, thus, the future of the large cold-water ice shelves in Antarctica. 
Acknowledgements We would like to thank S.S. Jacobs, T. Payne, J. Rae and M. Schröder for enlightening discussions, and W. Cohrs and D. Sidorenko for technical help and support. Two anonymous reviewers deserve a big Thank you for careful reading and providing good advice and helpful comments. This work was supported by funding to the ice2sea programme from the European Union 7th Framework Programme, grant number 226375. This is ice2sea contribution number ice2sea134.

\section{References}

1. Assmann KM, Hellmer HH, Jacobs SS (2005) Amundsen Sea ice production and transport. J Geophys Res. 110:C12013. doi:10.1029/2004JC002797

2. Cavalieri D, Parkinson C, Gloersen P, Zwally HJ (1996) Sea Ice Concentrations from Nimbus-7 SMMR and DMSP SSM/I-SSMIS Passive Microwave Data. National Snow and Ice Data Center. Digital media, updated yearly.

3. Connolley WM, Bracegirdle TJ (2007) An Antarctic assessment of IPCC AR4 coupled models. Geophys Res Lett 34:L22505, doi:10.1029/2007GL031648

4. Danilov S, Kivman G, Schröter J (2004) A finite element ocean model: principles and evaluation. Ocean Modelling 6:125-150.

5. Danilov S, Kivman G, Schröter J (2005) Evaluation of an eddy-permitting finite-element ocean model in the North Atlantic. Ocean Modelling 10:35-49. doi:10.1016/j.ocemod.2004.07.006.

6. Dupont TK, Alley RB (2005) Assessment of the importance of ice-shelf buttressing to ice-sheet flow. Geophys Res Lett 32:L04503. doi:10.1029/2004GL022024.

7. Holland PR, Jenkins A, Holland DM (2010) Ice and ocean processes in the Bellingshausen Sea, Antarctica. J Geophys Res. 115:C05020. doi:10.1029/2008JC005219.

8. Hellmer HH, Jacobs SS, Jenkins A (1998) Oceanic Erosion of a floating Antarctic glacier in the Amundsen Sea. In: Ocean, Ice and Atmosphere: Interactions at the Antarctic Continental Margin, Antarctic Research Series 75:83-99.

9. Hellmer, HH (2004) Impact of Antarctic ice shelf basal melting on sea ice and deep ocean properties. Geophys Res Lett 31:L10307.

10. Hellmer HH, Kauker F, Timmermann R, Determann J, Rae J (2012) Twenty-first-century warming of a large Antarctic ice-shelf cavity by a redirected coastal current. Nature 485(7397):225-228. doi:10.1038/nature11064.

11. Jacobs SS (1991) On the nature and significance of the Antarctic Slope Front. Marine Chemistry 35:9-24.

12. Jacobs SS, Hellmer HH, Doake CSM, Jenkins A, Frolich RM (1992) Melting of ice shelves and the mass balance of Antarctica. Journal of Glaciology 38(130):375-387.

13. Jacobs, S., H. Hellmer, and A. Jenkins (1996) Antarctic ice sheet melting in the Southeast Pacific. Geophysical Research Letters, 23(9), 957-960.

14. Jacobs S, Jenkins A, Giulivi C, Dutrieux P (2011a) Stronger sub-ice shelf ocean circulation undermining the Pine Island Glacier. Nature Geoscience 4:519-523. doi:10.1038/ngeo1188.

15. Jacobs S, Dutrieux P, Giulivi C, Rignot E, Schröder M, Stammerjohn S, Yuan X (2011b) The Getz Ice Shelf: Antarctica's top meltwater tap? IGS Symposium on Interaction of Ice Sheets and Glaciers with the Ocean, La Jolla, Abstract 60A127.

16. Jenkins A (1991) A one-dimensional model of ice shelfocean interaction. J Geophys Res. 96(C11):20671-20677.
17. Jenkins A, Jacobs SS (2008) Circulation and melting beneath George VI Ice Shelf, Antarctica. J Geophys Res. 113:C04013. doi:10.1029/2007JC004449.

18. Jenkins A, Dutrieux P, Jacobs SS, McPhail SD, Perrett JR, Webb AT, White D (2010) Observations beneath Pine Island Glacier in West Antarctica and implications for its retreat. Nature Geoscience 3:468-472. doi:10.1038/ngeo890.

19. Joughin I, Padman L (2003) Melting and freezing beneath Filchner-Ronne Ice Shelf, Antarctica. Geophys Res Lett 30(9):1477. doi:10.1029/2003GL016941.

20. Kusahara K, Hasumi H (2013) Modeling Antarctic ice shelf responses to future climate changes and impacts on the ocean. J. Geophys. Res. Oceans, 118, doi:10.1002/jgrc.20166.

21. Meier W, Fetterer F, Knowles K, Savoie M, Brodzik MJ (2006) Sea Ice Concentrations from Nimbus-7 SMMR and DMSP SSM/I-SSMIS Passive Microwave Data. National Snow and Ice Data Center. Digital Media, updated quarterly.

22. Nicholls KW, Abrahamsen EP, Heywood KJ, Stansfield K, Østerhus S (2008) High-latitude oceanography using the AUTOSUB autonomous underwater vehicle. Limnology and Oceanography 53(5, part 2):2309-2320.

23. Payne AJ, Cornford SL, Martin DF, Agosta C, van den Broeke MR, Edwards TL, Gladstone RM, Hellmer HH, Krinner G, Le Brocq AM, Ligtenberg SRM, Lipscomb WH, Ng EG, Shannon SR, Timmermann R, Vaughan D (2013) Sea-level contributions from the West Antarctic ice sheet over the 21st and 22nd centuries assessed using a chain of state-of-the-art atmosphere, ocean and ice sheet models under the A1B and E1 Greenhouse-gas forcing scenarios. Earth and Planetary Science Letters, submitted.

24. Potter JR, Paren JG (1985) Interaction between ice shelf and ocean in George VI Sound, Antarctica, in: Oceanology of the Antarctic Continental Shelf, edited by: Jacobs SS, Antarctic Research Series 43:35-58, American Geophysical Union.

25. Rignot E, Jacobs S, Mouginot J, Scheuchl B (2013) Ice Shelf Melting Around Antarctica. Science Express 341(6143):266-270, doi:10.1126/science.1235798.

26. Sidorenko D, Wang Q, Danilov S, Schröter J (2011) FESOM under Coordinated Ocean-ice Reference Experiment forcing. Ocean Dynamics. doi:10.1007/s10236-011-0406-7.

27. Thoma M, Grosfeld K, Lange MA (2006) The impact of the Eastern Weddell Ice Shelves on water masses in the eastern Weddell Sea. J Geophys Res. 111:C12010. doi:10.1029/2005JC003212.

28. Timmermann R, Beckmann A, Hellmer HH (2002a) Simulation of ice-ocean dynamics in the Weddell Sea. Part I: Model configuration and validation. J Geophys Res. 107(C3):10.1029/2000JC000741.

29. Timmermann R, Hellmer HH, Beckmann A (2002b) Simulation of ice-ocean dynamics in the Weddell Sea. Part II: Interannual variability $1985-1993$. J Geophys Res. 107(C3):10.1029/2000JC000742.

30. Timmermann R, Danilov S, Schröter J, Böning C, Sidorenko D, Rollenhagen K (2009) Ocean circulation and sea ice distribution in a finite element global sea ice - ocean model. Ocean Modelling. doi:10.1016/j.ocemod.2008.10.009.

31. Timmermann R, Le Brocq A, Deen T, Domack E, Dutrieux P, Galton-Fenzi B, Hellmer HH, Humbert A, Jansen D, Jenkins A, Lambrecht A, Makinson K, Niederjasper F, Nitsche F, Noest OA, Smedsrud LH, Smith WHF (2010) A consistent dataset of Antarctic ice sheet topography, cavity geometry, and global bathymetry. Earth Syst. Sci. Data 2:261-273. doi:10.5194/essd-2-261-2010. 
32. Timmermann R, Wang Q, Hellmer HH (2012) Ice shelf basal melting in a global finite-element sea ice - ice shelf - ocean model. Annals of Glaciology, 53(60), 303-314, doi:10.3189/2012AoG60A156. 